\title{
Organizational and Technological Solutions for Performing Works Using Specialty Equipment
}

\author{
Boris Zhadanovsky and Vladimir Bazanov* \\ Moscow State University of Civil Engineering, Yaroslavskoe shosse, 26, Moscow, 129337, Russia
}

\begin{abstract}
Relevance of applying factory-assembled unit installation method in the contemporary construction is stated. Foreign experience is shown and main foreign manufacturers of crawler cranes and gantry cranes are given. Basic technical characteristics and design parameter of foreign and domestic cranes are quoted. The experience of gantry crane usage is discussed. Technical characteristics of gantry cranes from Sarens, Enerpac, Riggers Manufacturing, LiftSystems, Hydrolast, and Enerprom are given.
\end{abstract}

\section{Introduction}

The main direction in the contemporary construction is dry construction of civil and industrial buildings and facilities allowing their fast erection at minimal labor cost on the construction site. Engineering facilities are erected from heavy-weight large-sized blocks maximally ready for operation.

The comprehensive installation process consists of a number of steps, which are performed in sequence from delivery of prefabricated elements to the construction site and their assembly into a finished facility according to the design documentation and method statement. In prefabricated unit assembly, individual structures are enlarged into flat or spatial blocks. This allows performing construction works, which are difficult to do at height, at zero level. During installation using comprehensive construction and process blocks, process equipment and engineering lines are mounted onto construction structures. Maximal structural enlargement is achieved when finished facilities are installed: a facility is fully assembled at the ground level and thereafter put on place.

Installation works are connected with rigging of construction structures, products, and process equipment. Installation methods are continuously improved thanks to the development of lifting mechanisms and transport means. Various installation methods and types require use of different types of carrying and lifting machines and mechanisms to provide production process speed, reliability and safety $[1,2]$. In preparing organizational and technological documentation, the choice of installation method determines the technological sequence of installation works and largely determines the technical and economic parameters, labor productivity, quality of works, energy intensiveness, and mechanization level. Orderly use of specialty mechanisms for processing extra-heavy

*Corresponding author: bazanov_kim@mail.ru 
cargoes allows reducing considerably the scope of auxiliary works, construction cost and completion period [3].

Among manufacturers of specialty carrying and lifting equipment, a number of major companies can be highlighted:

Liebherr is a German company specializing in the manufacture of lifting mobile and crawler cranes. Heavy mobile cranes feature a lifting capacity of up to 1200 tons, that of crawler cranes reaches 3000 tons.

Sarens is a group of companies with its headquarters in Belgium; its staff number exceeds 3000. The company's early turnover reaches $420 \mathrm{M}$ euro. The company The company delivers a full 'turnkey' package of rigging and installation works using both equipment of its own make and that manufactured by others. Lifting systems Sarlift 750 (the capacity of each foot is 75 tons), 1000 (100 tons), 2500 (250 tons) are developed by the Sarens special R\&D unit. SLU rigging system having a force of up to 2000 tons per each pusher enables movement over rigging guides of arbitrary width.

In Russia, crawler cranes are commercially manufactured by two factories: The Chelyabinsk Mechanical Factory (CMF) and The Ulyanovsk Mechanical Factory No.2 (UMF No. 2). The lifting capacity of cranes is 16 to 300 tons.

Enerpac (Holland), employing over 1000 employees in 22 countries all over the world, focuses on the development and manufacture of high-pressure hydraulic mechanisms. Enerpac stock-produced equipment provides controlled lifting, movement, and precise positioning of cargo. Besides, in some cases, company specialists apply a comprehensive approach implying combined use of standard hydraulic equipment, steel structures, and electronic control systems. The company develops hydraulic and rope hoists, sliding systems, self-propelled modular platforms.

Riggers Manufacturing Com $\neg$ pany (USA) is a developer of gantry-type hydraulic lifting systems. Manufactured late in the 80 s of the previous century, some systems function up till now and comply with the current safety standards.

LiftSystems, Inc. (USA), founded by a former employee of Riggers Manufacturing, is engaged in the manufacture of mobile gantry cranes and mobile self-propelled cranes for lifting and carrying various cargoes of any outer sizes weighting up to 1250 tons. LiftSystems mobile gantry cranes are supplied to more than 50 countries of the world and represent a system of props with hydraulic cylinders arranged on a mobile platform.

Hydrolast hydraulic equipment factory (Saint Petersburg, Russia) is a leading Russian vendor of hydraulic equipment for heavy and general engineering industry. Hydrolast has seventeen service centers in Russia, Byelorussia, Kazakhstan, and Ukraine.

Enerprom (Irkutsk, Russia) designs, manufactures, and supplies hydraulic equipment for various industries. Enerprom bridge-building hydraulic equipment includes hydraulic systems for longitudinal cyclic launching of bridge structures. Gantry hydraulic lifts are designed to address carriage transfer tasks, perform installation/de-installation of heavyweight large-size equipment with high level of accuracy without using lifting cranes in confined spaces of production and construction sites.

\section{Methods and Results}

The factory-assembled unit installation method of installation of large-size and heavyweight items and structures implies use of various specialty equipment: tower and boom cranes, gantry lifts, hydraulic and rope jacks, self-propelled modular platforms, sliding systems, derricks, rigging pushers, lifting hydro cylinder synchronization systems and lifting cargo positioning systems. This paper gives a comparative analysis of lifting crawler cranes and gantry systems. 


\section{Discussion}

\subsection{Crawler Cranes}

Crawler cranes combine mobility, high lifting capacity, and lifting height. They consist of a crawler track undercarriage and a turntable platform with working attachments: a boom, boom lift and cargo lifting/lowering tackle system, cargo gripper. A cabin with a control panel, platform rotation mechanisms, main lift hoists and a diesel electric unit, a boom are mounted on the turntable platform. Cranes have a wide range of different configurations: with a main boom; of tower-boom make, including equipped with a moving (shunting) jib; with a derrick counter-pillar; suspended/dolly superlift. Crawler cranes are operated without outboard supports (outriggers) and can travel without a prepared route across a construction site, and within a specially prepared construction site - with hooked cargo. This type of cranes is widely used in projects where there is a considerable scattered scope of work, in heavy, power and hydraulic engineering construction.

The advantages of crawler cranes include high lifting capacity and cargo lifting height, compactness, ability to travel carrying large-size cargo, mobility and maneuverability, cost effectiveness, and ability to run at low temperatures. Their main drawback is complex transportation and necessity of complete disassemble into parts, furthermore, the main part of the structure weighting more than 100 tons cannot be disassembled.

In Russia, crawler cranes of 25-250-ton capacity are manufactured by three factories:

- The Ramensky Mechanical Factory [4] manufactures SKG series cranes (SKG-505 having a lifting capacity of 50 tons and SKG-631 having a lifting capacity of 63 - 100 tons),

- The Chelyabinsk Mechanical Factory, JSC (CMF) manufactures DEK series cranes, which have a lifting capacity of up to 100 tons. [5],

- The Ulyanovsk Mechanical Factory No. 2, JSC (UMF No.2) manufactures MKGS series cranes, which have a lifting capacity of up to 300 tons [6].

MKGS cranes have a DC electrical drive and are fed from external mains or a diesel power plant. Complete modular diesel power plant DES-100 is a backup or self-generated power supply consisting of a special noise-absorbing insulated mini-container and a diesel generator, self-contained power supply equipment and life support systems installed therein. Its modular design makes crane transportation and installation significantly easier. MKGS-250 crane functions on outriggers, is equipped with interchangeable boom and tower boom equipment, removable driven crawler trolleys thanks to which it can move selfpropelled around the site unloaded but equipped with various boom and tower boom equipment, and with a 125-ton cargo on the main boom.

Some types of crawler cranes and their basic technical characteristics are given in table 1 .

Table 1. Crawler Crane Characteristics

\begin{tabular}{lccccc}
\hline Crane Type & $\begin{array}{c}\text { Capacity, } \\
\text { tons }\end{array}$ & $\begin{array}{c}\text { Maximal } \\
\text { Lift Height, } \\
\mathbf{m}\end{array}$ & $\begin{array}{c}\text { Boom-out, } \\
\mathbf{m}\end{array}$ & $\begin{array}{c}\text { Weight, } \\
\text { tons }\end{array}$ & $\begin{array}{c}\text { Power Plant, } \\
\text { availability/kW }\end{array}$ \\
\hline DEK-631A & 63 & 71.2 & 39.7 & 83.5 & yes $/ 100$ \\
DEK-1001 & 100 & 68.4 & 55 & 114 & yes/ \\
MKGS-100.1 & $100 / 48$ & $20.7 / 55.2$ & $6.5 / 9$ & 130 & yes $/ 100$ \\
MKGS-125.1 & $125 / 19.5$ & $64 / 95$ & $6.5 /$ & 142 & yes $/ 100$ \\
MKGS-250 & $250 / 22$ & $29 / 123$ & $8.0 / 22$ & 320 & yes $/ 100$ \\
MKGS-300 & $300 / 22$ & 1123 & $6.5 /$ & 320 & yes/
\end{tabular}

Domestic crane-building is characterized by use of a diesel electric drive. Thanks to its domestic aggregate base, the crane has an advantageous price. The technology has been mastered over the course of decades; diesel electric cranes feature good maintainability, 
which is supported at least by durability of machines made 20, 30, and 40 years ago. Frostresistant make of cranes, designed for operation at $-40^{\circ} \mathrm{C}$, allows successful operation of this equipment in regions with cold climatic conditions. Heavy crawler cranes can run both from their own diesel power plant and from external $380 \mathrm{~V} / 50 \mathrm{~Hz}$ three-phase mains, and at a remote project where there is no power supply, the crane can be used as a power plant. Currently, both CMF and UMF No.2 already manufacture some models of hydraulic cranes of up to 40ton capacity. A hydraulic drive has allowed achieving better characteristics: smooth drive operation, low touch-down speed ensuring accuracy during installation works. Special installation cranes made by CMF and UMF No.2 have proven to be reliable, easy to operate, low-maintenance, and simple to repair. For many years, they have been successfully operated at large construction projects in Russia, neighboring countries and beyond.

Figures 1 and 2 show DEK and MKGS cranes.

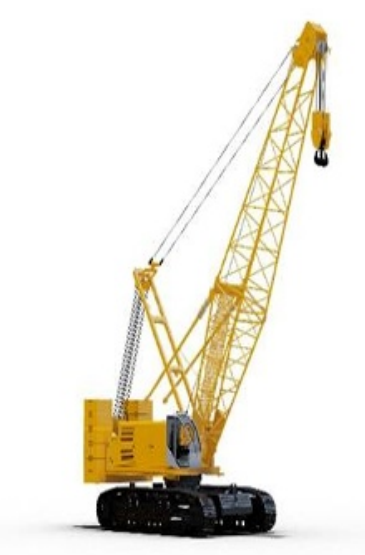

Fig. 1. DEK- 631

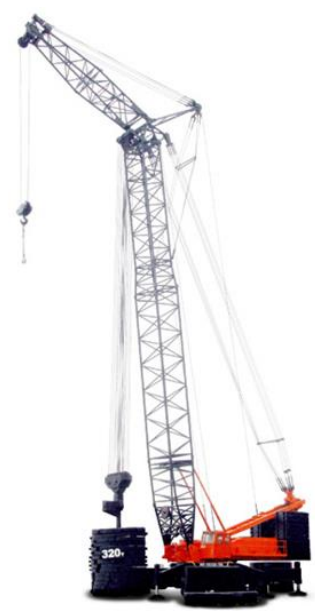

Fig. 2. AMKGS-250

Among foreign vendors supplying crawler cranes to the Russian market, Liebherr is the leader. Crawler cranes for construction and installation made by German Liebherr can lift cargoes weighing 350 to 3000 tons [7]. The maximal lift height is $245 \mathrm{~m}$. One of the methods to increase lifting capacity and operation range of cranes is usage of counterbalances with a derrick ballast. The derrick ballast is used as a suspended ballast or a ballast trolley and increases the load moment. In guide frame-free cranes, one can change the outreach of suspended ballast at full load with the help of the derrick boom. When a guide frame is fitted, the ballast trolley and suspended ballast have a larger operation range.

It is noteworthy to mention parallel boom PowerBoom developed by Liebherr (figure 3). Two additional standard lattice sections are installed in parallel to each other in the lower part of the main boom, which significantly increases stability of the lattice boom, so the capacity of large crawler cranes grows by more than $50 \%$. This efficient design solution makes it possible for the crane to reach a capacity equal to the next capacity class. 

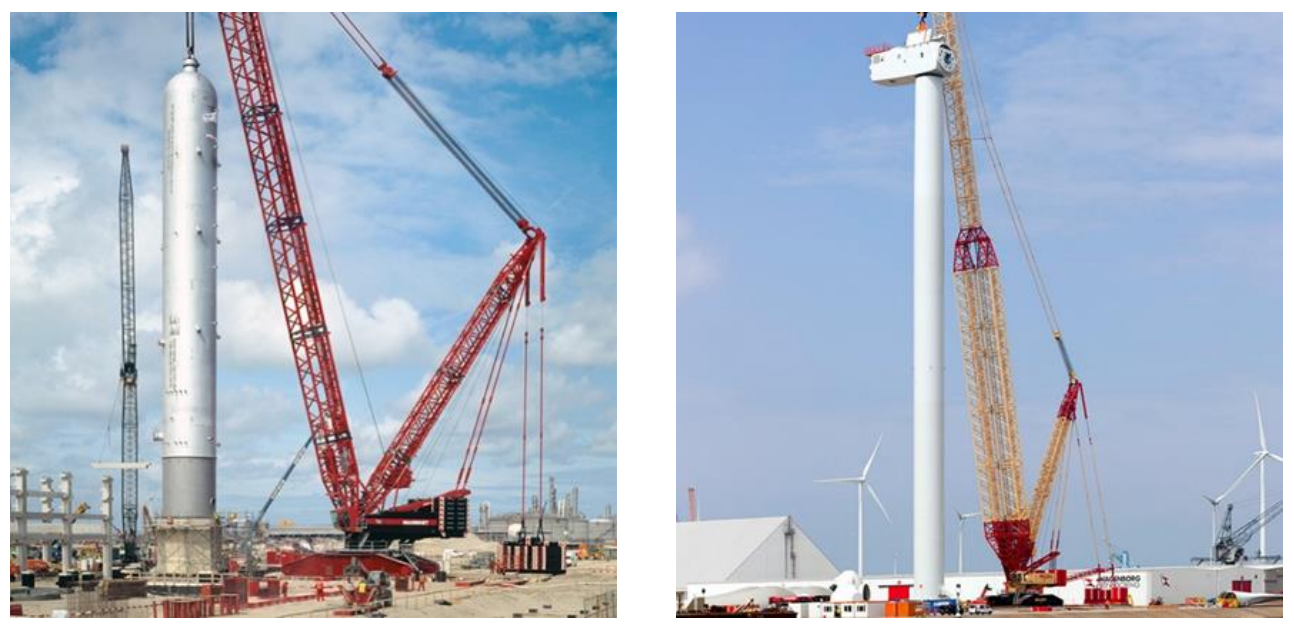

Fig. 3. Crawler cranes made by Liebherr

\subsection{Gantry Lifts}

Gantry complexes are designed to carry and move non-standard and large-size equipment in a confined space with high positioning accuracy.

Hydraulic gantry systems (gantry lifts) allow to move equipment vertically, longitudinally, and transversally, reverse and turn equipment, pick and place equipment from transport means in a confined space of a construction site or functioning business in cases when it is impossible to use cranes of other types. A hydraulic gantry lift is a portal with pillars telescoped upwards by hydraulic hoists - jacks. Hydraulics ensure safe lifting and positioning of heavy cargoes. Usage of hydraulic lifts is less costly compared to renting various types of mobile cranes. Thanks to their efficiency and multitask capability, hydraulic installation systems have become standard lifting equipment nowadays.

Sarens [8] produces a range of lifting systems Sarlift 750 (the capacity of each foot is 75 tons), 1000 (100 tons), 2500 (250 tons). The systems consist of the following elements: a hydraulic station with a diesel or electric drive, 4 lifting pillars with cylinders and locking mechanisms, various beams and girders, synchronization and safety valves. All systems are equipped with an electronic weighing system. Cylinders move inside feet, resting on fixing anchors. The main advantages of Sarlift systems are their fast erection, small dimensions, and safe design. Rigging sledges fitted with support hydraulic jacks integrated into controlled hydraulic circuits provide even distribution of forces between all bearing points. SLU crigging system that has a force of up to 2000 ton per each pusher allows movement over rigging guides of an arbitrary width. Its modular principle makes it possible to create a necessary configuration for each specific task.

The maximal lift height might reach 40 meters depending on cargo weight and dimensions and possibility of installing additional bracing (figure 4 ). The capacity of stockproduced items is 75 to 250 tons per one foot and the cylinder stroke is 500 to $250 \mathrm{~mm}$. 


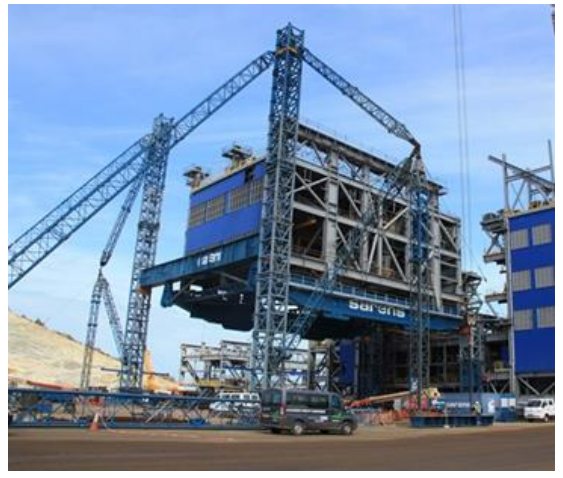

Fig. 4. Sarens lifting systems

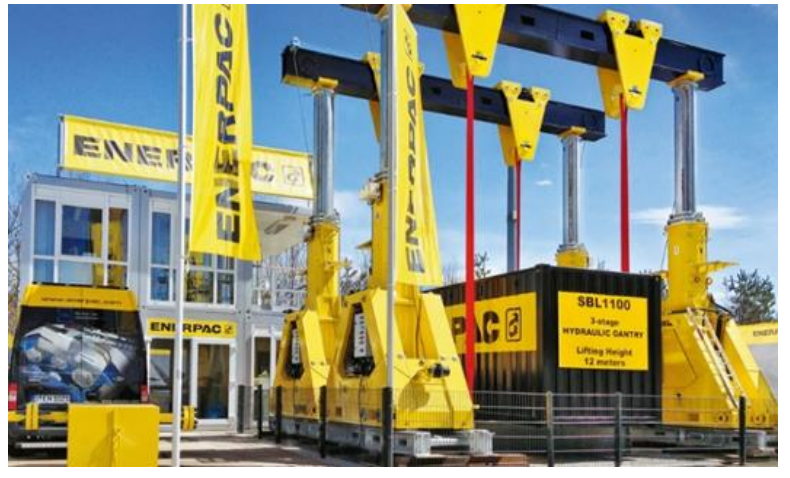

Fig.5. Enerpac hydraulic lifts

Enerpac [9] offers three series of hydraulic lifts. Three models of SL series may be supplied with two or three hydraulic cylinder outlets. The most powerful of the three models of SBL series has the maximal capacity of 1100 tons at $12 \mathrm{~m}$ lift height. The entire series is equipped with octagonal booms ensuring safety standards during lateral dynamic loads. New lifts of MBL series have a special design (as a square tower with four cylinders at corners in each lifting section) for extra-high stability under lateral dynamic loads and maximal capacity at maximal outreach. MBL complex can lift 600 tons to a height of $18 \mathrm{~m}$. Computer systems controlling synchronous lifting of cargoes provide optimal equipment stability and safety of works. Hydraulic equipment is built into the lifting tower frame and do not require laying high-pressure sleeves outside. Intelli-Lift remote control system automatically synchronizes feet and displays current information about lifting and loading. Among projects implemented using Enerpac lifts, installation of gas aggregates and AC generators, each weighting hundreds tons, with the help of hydraulic gantry crane SBL1100 can be mentioned (figure 5). Two hydraulic gantry cranes Enerpac SBL1100SP were enough to lift a hydrocracking reactor (the reactor's weight is 1400 tons, its length is 42.5 $\mathrm{m}$, and its diameter is $5.2 \mathrm{~m}$ ) from roller supports, move, put onto shipping keelblocks, and position for subsequent transportation on a self-propelled platform.

The today's range of products made by Riggers Manufacturing Com $\neg$ pany includes EZLifter series lifts [10]. Each foot of EZLifter lift is a fully self-contained assembly consisting of an electric engine, hydraulic pump, hydraulic distribution valves, tank, and epicyclic gear drive of stroke. The EZLifter foot includes 4 hydraulic cylinders mounted onto the top beam with joint hinges (figure 6). Lift feet move back and forth over tracks with the help of hydraulic motors. CARL control system synchronizes cargo lifting, lift movement and lateral shift, monitors lift height and hydraulic system pressure. Erection needs a minimal scope of works: installation of the lift onto tracks and making connections. The time of installation and setup on the site is less than two hours. 

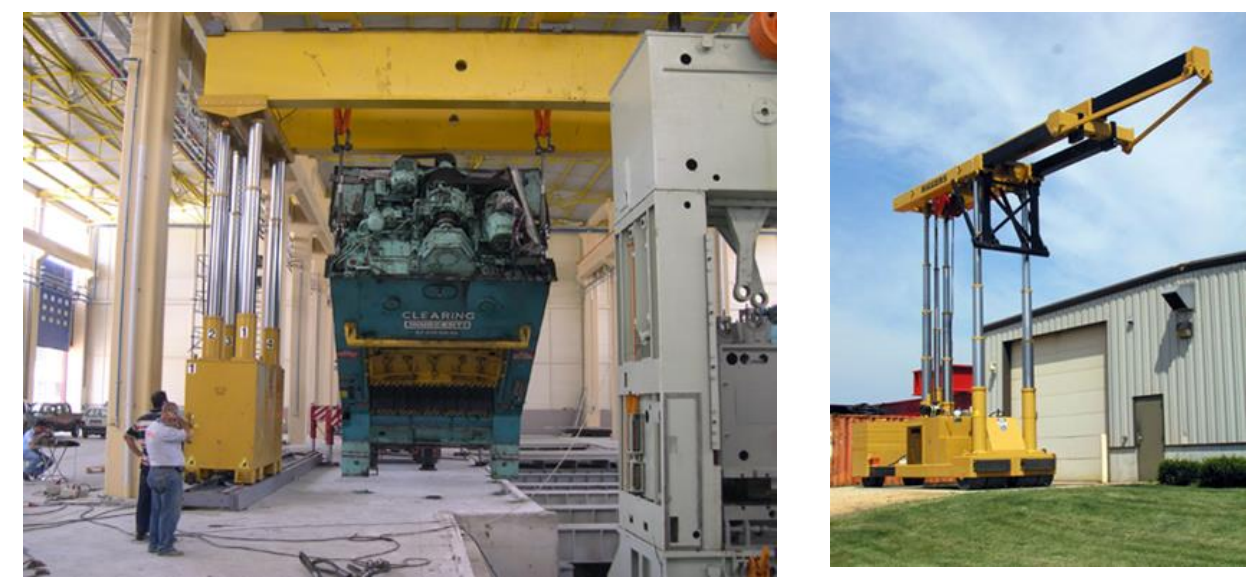

Fig. 6. Lifts from Riggers Manufacturing Company

Lift Systems, Inc. (USA) produces a range of PowerTower hydraulic gantry systems [11], which have a capacity of 400 to 1500 tons and lift height of 4 to $14 \mathrm{~m}$. LiftSystems mobile gantry cranes represent a system of pillars with hydraulic telescopic cylinders on a mobile platform. Systems may include two, four, or more pillars (figure 7). Their design provides fast installation in place without special preparation, fast disassembly and transportation. All gantry systems have a standard scope of supply that includes two power aggregates. This allows easy system splitting into two packages or its use to lift long structures and items.
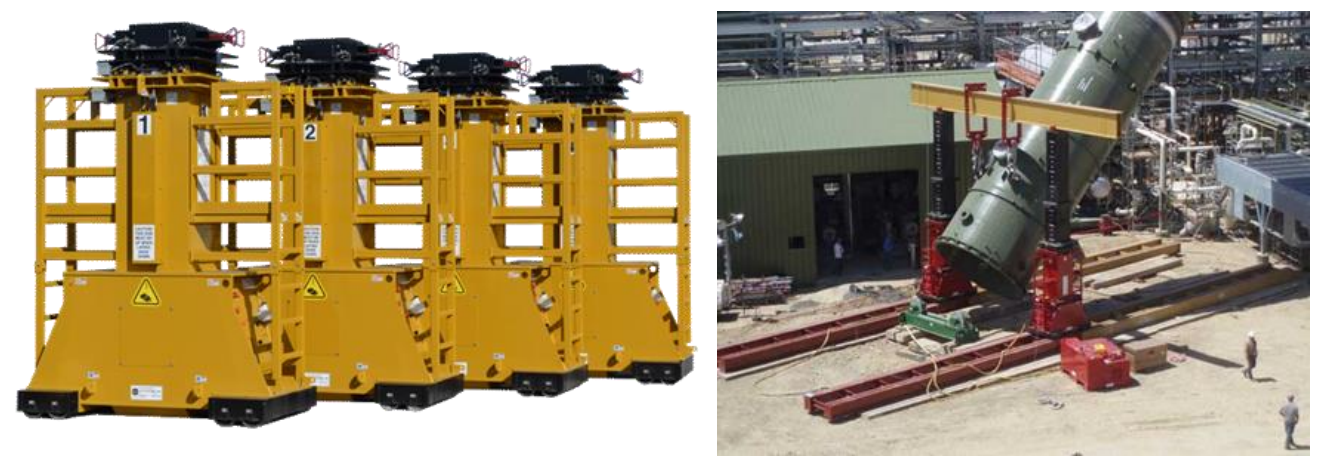

Fig.7. LiftSystems gantry systems

Hydrolast hydraulic equipment factory (Stary Oskol, Russia) is a leading Russian vendor of hydraulic equipment for heavy and general engineering industry [12]. The factory's production program includes two- and four-pillar gantry lifts MPK (figure 8), consisting of hydraulic towers of 12 to 100-ton capacity (each tower has its own hydraulic station and stroke drive), and upper supporting beams that have a length of 6,8 , and $10 \mathrm{~m}$. Lifts move over $3 \mathrm{~m}$-long block-rails. All towers are controlled from a common control panel. The hydraulic installation system consists of a system of hydraulic jacks, is very safe in operation thanks to low working pressure than does not exceed $20 \mathrm{MPa}$. System capacity depends on the number of jacks (the number of jacks depends on the models and varies between two and eight) and equals to 40 to 400 tons; the positioning accuracy is $0.1 \mathrm{~mm}$, and the cargo movement speed is $12 \mathrm{~cm}$ per minute on average. The maximal height of cargo lifting is $8230 \mathrm{~mm}$. The hydraulic installation system is equipped with GidrolastSafe control and synchronization system providing visualization, monitoring, and data 
processing. In the course of vertical movement of cargo, the automatic system traces and makes up for occurring skewness. A backup remote wireless control system and antioverload protective systems are installed. A specific feature of MPK lifts is their great number of fasteners for ropes enabling high-accuracy positioning of non-standard and oversize equipment along length, width, and height, and move, rig, and install any cargoes from containers and tank-cars to nuclear reactors. The design is made of standard unitized (easily to replace and install) assembly units and parts; the warrantied number of cycles is thirty thousand.

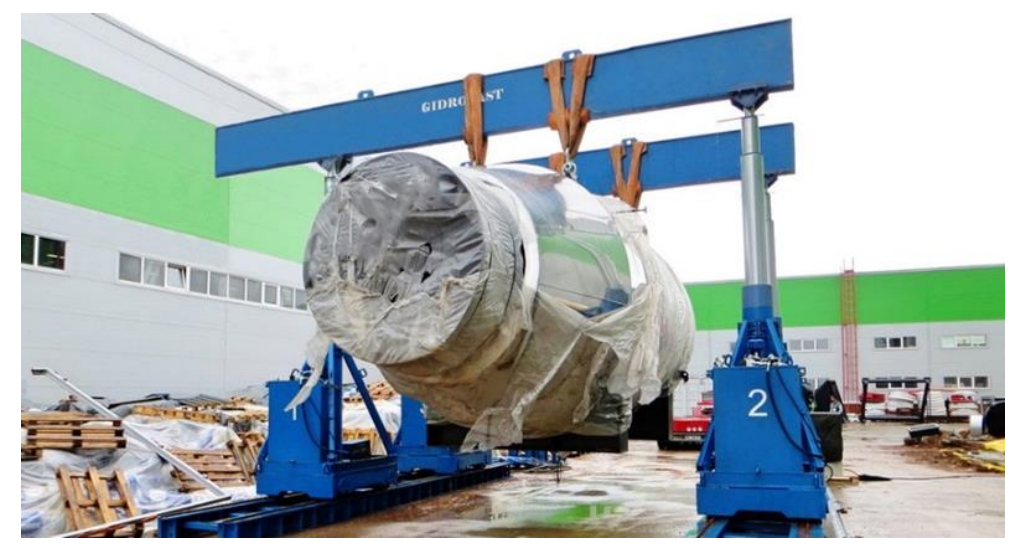

Fig. 8. Four-pillar lift from Hydrolast

\section{Conclusion}

At present, carrying and lifting, and rigging equipment can play a key role rather than auxiliary as regards reduction of construction completion period. The degree of specialization and mechanization of carrying and lifting machines for installation of largesize and heavy items and structures grows. The choice of carrying and lifting equipment requires thorough examination and taking into account the specifics of a project and designed construction methodology. In many cases, development of technological processes and installation solutions is unique and needs involvement of lifting equipment developers.

The correct choice of types of carrying and lifting equipment and organizational and technological solutions is the key factor to ensure high efficiency and safety of works. Costeffectiveness and recommendations on the choice of carrying and lifting equipment for different projects depend, first of all, on the cost of equipment and installation. The best option must ensure least labor intensity and cost of installation and guarantee safe working conditions.

\section{References}

1. Colin Gray \& James Little 1985 A systematic approach to the selection of an appropriate crane for a construction site Construction Management and Economics 3:2 pp 121-144, DOI: 10.1080/01446198500000010

2. Aviad Shapira, Gunnar Lucko, Clifford J. Schexnayder 2007 Cranes for Building Construction Projects Journal of Construction Engineering and Management Volume 133 Issue 9, DOI: 10.1061/(ASCE)0733-9364(2007)133:9(690)

3. Drogovoz P A, Popovich A L 2014 Comparative analysis of technologies for lifting and 
installation of heavy equipment in the Achinsk Oil Refinery Reconstruction Project Engineering Journal: Science and Innovations issue 3.

4. URL: http://engjournal.ru/catalog/indust/hidden/1223.html (access date: 23.11.2018)

5. Ramensky Mechanical Factory: [site]. URL: http://www.rammeh.ru/ (access date: 11.12.2018)

6. Chelyabinsk Mechanical Factory: [site]. URL: https://www.cmz.ru/ (access date: 11.12.2018)

7. Productcenter: [site]. URL: https://productcenter.ru/products/3453/kran-montazhnyimkgs-250 (access date: 11.12.2018)

8. Liebherr: [site]. URL: https://www.liebherr.com/ (access date: 14.12.2018)

9. Sarens: [site]. URL: http://www.sarens.com/ (access date: 14.12.2018)

10. Enerpac: [site]. URL: https://www.enerpac.com (access date: 14.12.2018)

11. Riggers: [site]. URL: http://www.riggers.com/ (access date: 18.12.2018)

12. Lift Systems, Inc.: [site]. URL: http://www.lift-systems.com/ (access date: 18.12.2018)

13. Gidrolast: [site]. URL: http://www.gidrolast.ru/ (access date: 18.12.2018) 